Check for updates

Cite this: RSC Adv., 2017, 7, 52091

Received 11th September 2017 Accepted 20th October 2017

DOI: 10.1039/c7ra10094a

rsc.li/rsc-advances

\section{Rapid and sensitive detection of trace malachite green and its metabolite in aquatic products using molecularly imprinted polymer-coated wooden-tip electrospray ionization mass spectrometry}

\author{
Yanying Huang, $\dagger^{\mathrm{a}}$ Yanfang Ma, $\uparrow^{\mathrm{b}}$ Huawen Hu, (D) $\dagger^{\mathrm{a}}$ Pengran Guo, ${ }^{\mathrm{b}}$ Lei Miao, ${ }^{\mathrm{a}}$ \\ Yunyun Yang*b and Min Zhang*a
}

\begin{abstract}
In this study, a molecularly imprinted polymer-coated wooden-tip (MIPCWT) electrospray ionization mass spectrometry (ESI-MS) method was developed for rapid and sensitive detection of trace malachite green (MG) and its metabolite in aquatic products. Such a method was realized by applying a silicone-modified acrylate molecularly imprinted emulsion (SMAMIE) onto the surface of wooden tips to specially design a MIPCWT solid-phase micro-extraction (SPME) probe for selective enrichment of MG and its metabolite from aquatic products. Subsequently, a high voltage and some spray solvent were applied to the MIPCWT SPME probe, and ESI was induced for direct MS analysis under ambient and open-air conditions. The MIPCWT-SPME probe exhibits a high enriching capacity of approximately 1500-2000 fold toward MG and leucomalachite green (LMG), with detection limit reaching $0.01 \mu \mathrm{g} \mathrm{L}^{-1}$. In addition, a good linearity is obtained for both MG and LMG, with correlation coefficient values $\left(R^{2}\right)$ of no less than 0.998. The present method was successfully applied to analyze MG and LMG in real-life tap water, river water and fish samples, and good recoveries in the range of 93-103\%, 92-108\% and 106-113\%, respectively, were found. All of these demonstrated that our developed MIPCWT-ESI-MS method holds great potential for rapid, direct, sensitive, and reliable detection and analysis of trace veterinary drug residues in aquatic products.
\end{abstract}

\section{Introduction}

Various industries relating to chemical synthesis (such as textiles, ceramics, printing, leather and plastics) are discharging an increasing quantity of effluents containing dye wastes. The widespread use of synthetic dyes, as one of the most important and concerning categories of contaminants nowadays, poses a serious threat to the aquaculture environment, due to their hazardous nature, high stability and complex aromatic structures. ${ }^{1,2}$ Malachite Green (MG), also known as aniline green and basic green 4, etc., is a cationic azo-compound with three aryl groups. MG is classified as a Class II Health Hazard by reason of its toxicity to human cells, induction of liver tumor formation, and potential risk to aquatic life. ${ }^{3,4}$ When injected into an organism, MG can be readily converted to leucomalachite green

${ }^{a}$ School of Materials Science and Energy Engineering, Foshan University, Foshan 528000, China. E-mail: zhangmin@gic.ac.cn

${ }^{b}$ Guangdong Engineering and Technology Research Center for Ambient Mass Spectrometry, Guangdong Provincial Key Laboratory of Emergency Test for Dangerous Chemicals, Guangdong Institute of Analysis (China National Analytical Center Guangzhou), 100 Xianlie Middle Road, Guangzhou 510070, China. E-mail: yy_yang@vip.126.com

$\dagger$ These authors contributed equally to this work.
(LMG), which is most likely to accumulate in the serum, liver, kidney, muscle, fertilized eggs and other tissues of the organism, causing teratogenic, carcinogenic and mutagenic potential to humans. ${ }^{5-7}$ On the other hand, owing to its high efficiency and low cost, MG has been widely used as a biological repellent and insecticide in aquaculture industries because it is effective at treating aquatic mildew, gill mildew and parasitic diseases in aquatic products. ${ }^{8,9}$ Considering the growing importance and significance of environmental protection, exploration of rapid and sensitive methods for sensing and detection of various contaminants, including MG, has become a hot topic over recent decades. ${ }^{10,11}$ However, it remains a great challenge to develop a novel, sensitive, and rapid method for MG detection, with cost-effective and portable probes developed as the key component. Herein, we report the very first example of a novel, rapid, sensitive, and low-cost method for detection of trace malachite green and its metabolite in aquatic products using molecularly imprinted polymer-coated wooden-tip (MIPCWT) based electrospray ionization mass spectrometry (ESI-MS).

Liquid chromatography (LC) coupled with mass spectrometry (MS) is one of the most frequently used approaches to detect and quantify MG and its metabolite in different matrices, 
such as water, aquatic products, and fish feedstuffs. However, conventional LC-MS methods are generally labor-intensive and time-consuming, since multi-step sample pretreatments are needed for enrichment of trace analytes to a detectable level. ${ }^{8}$ Moreover, matrix interference needs to be eliminated to obtain better-resolved detection results, requiring additional steps and hence consuming more time. A protracted chromatographic separation is also required, rendering this traditional method highly labor-intensive and time-consuming. It is therefore highly desirable to explore a method for rapid, direct, sensitive, and reliable analysis of MG and its metabolite in complex matrices.

Ambient MS gives such an opportunity. During the past two decades, a series of ambient ionization techniques, such as desorption electrospray ionization (DESI), ${ }^{12}$ extractive electrospray ionization (EESI), ${ }^{\mathbf{1 3 - 1 5}}$ direct analysis in real time (DART), ${ }^{16-18}$ probe electrospray ionization (PESI), ${ }^{19,20}$ lowtemperature plasma (LTP), ${ }^{21,22}$ desorption corona beam ionization (DCBI), ${ }^{\mathbf{2 3 2} 24}$ laser ablation electrospray ionization (LAESI), ${ }^{25-27}$ paper spray, ${ }^{28-32}$ and wooden-tip ESI have been developed, ${ }^{33-40}$ which facilitate rapid, direct and straightforward analysis of various samples under ambient and open-air conditions with minimal or no sample pretreatment. However, MG and its metabolite usually present in the environment or aquatic products with a trace level of concentrations (around the $\mu \mathrm{g} \mathrm{L}^{-1}$ level), and the compositions of matrices are also unknown with complexities. In this regard, it is rather difficult to directly detect $\mathrm{MG}$ and its metabolite using the existing ambient MS methods.

Solid-phase micro-extraction (SPME) coupled with ambient MS has been developed to directly detect complex samples with high sensitivity and low matrix interference. ${ }^{\mathbf{4 1 - 4 4}}$ To date, SPME has been successfully coupled to several ambient ionization techniques, such as DESI, ${ }^{45}$ DART, ${ }^{46-48}$ LTP, ${ }^{49,50}$ and DCBI. ${ }^{23,24}$ In addition, direct ionization of SPME fibers, ${ }^{51}$ a SPME probe coupled with nanoelectrospray ionization (nanoESI), ${ }^{52-54}$ coated blade spray (CBS), ${ }^{55-57}$ and surface-coated wooden-tip electrospray ionization (SCWT-ESI) ${ }^{58,59}$ have been explored as novel strategies for rapid extraction of trace analytes for direct MS analysis of complex samples. Direct desorption/ionization can also be realized by MS analysis. Considering the complexity of aquatic products, SPME with higher selectivity and better stability should be developed.

Molecularly imprinted polymers (MIPs) have drawn significant attention recently owing to their specific recognition and enrichment of MG molecules, even in trace analysis. ${ }^{60-63}$ MIPs have been successfully used as cartridge column fillers for realizing solid-phase extraction (SPE) of MG in aquatic products in several previous studies. ${ }^{64-67}$ However, before the analytical process based on the high selectivity of MIPs and high sensitivity of modern instruments (e.g., HPLC or HPLC-MS), the initial sample preparation is generally complex and tedious, and involves multiple solvent extractions, centrifugation, rotary evaporation, solid phase extraction and elution. ${ }^{65,68}$ Even though advances have recently also been made in the fabrication of various kinds of MIPs for determination of MG in aquatic products, such as magnetic MIPs, ${ }^{68-71} \mathrm{CdTe}$ quantum dots, ${ }^{8,72}$ carbon nanotubes ${ }^{73}$ or polymeric dopamine hydrochloride film, ${ }^{74}$ it remains time-consuming and labor-intensive to employ these MIPs in the detection of trace MG in aquatic products.

In this article, we report the very first example of exploring a molecularly imprinted polymer-coated wooden-tip electrospray ionization mass spectrometry (MIPCWT-ESI-MS) method (with cost-effective and portable probes developed as the key component) for rapid and sensitive analysis of MG and its metabolite in water and fish samples. We simplify the extraction and enrichment processing of MG by using a pinprick, in this case a wooden tip, through fish muscles for sampling. A MIPCWT-SPME probe that possesses imprinting cavities of MIPs with specific identification to MG is then specially designed for selective enriching and rapid detection of trace MG. The detection of trace MG from water and fish samples using a real-time direct analysis MS method is finally realized. In this study, a comparison is also made between the present method and many reported state-of-the-art approaches. The main content of this study is schematically illustrated in Fig. 1.
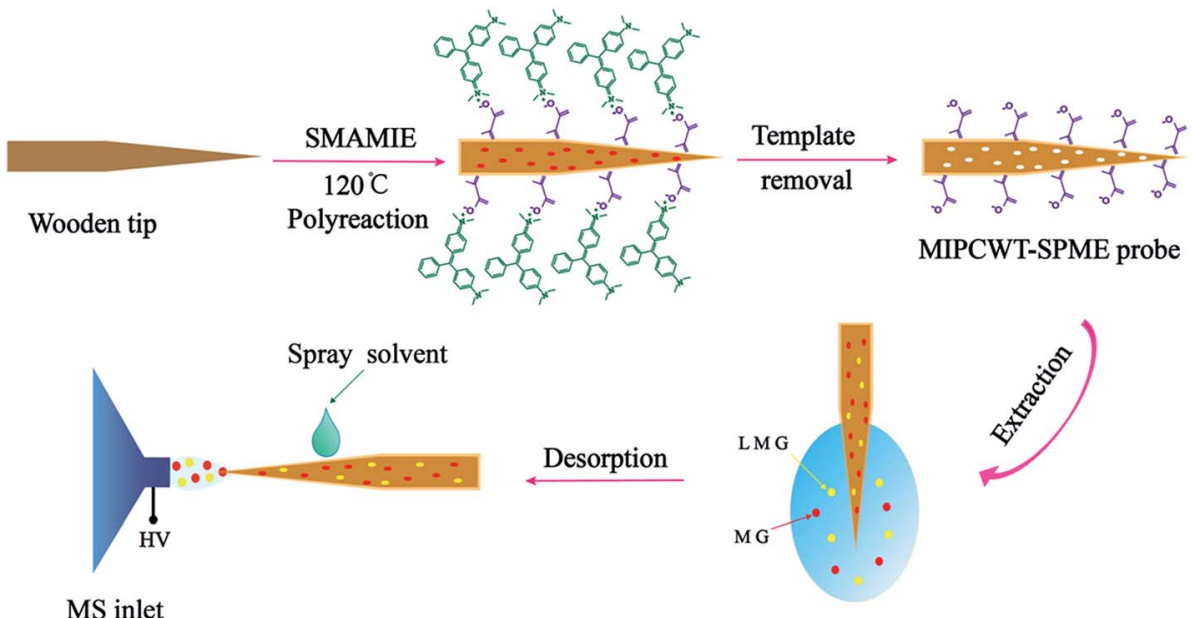

MS inlet

Fig. 1 Schematic diagram showing the detection of MG and LMG in water by the present MIPCWT-ESI-MS method. 


\section{Experimental}

\section{Materials and reagents}

Wooden toothpicks (birch wood) were purchased from a PARKnSHOP supermarket in Hong Kong. Reference standards of MG, LMG and $d_{5}$-MG were purchased from Witega (Berlin, Magnusstrasse 11, Germany). Thioflavin $\mathrm{T}$ (ThT) and rosolic acid were obtained from Shanghai Macklin Biochemical Co., Ltd (Shanghai, China). Tris(2-methoxyethoxy) vinylsilane (A172) was provided by Fisher Scientific (Geel, Belgium). 2,3Dichloro-5,6-dicyano-1,4-benzoquinone (DDQ, 98\% purity) was purchased from Sigma-Aldrich (St. Louis, MO, USA). Highpurity chromatographic grade acetonitrile and methanol $(\mathrm{MeOH})$ were obtained from Fisher Scientific (Geel, Belgium). Analytical grade methacrylic acid (AA), styrene (St), butyl acrylate (BA), methyl methacrylate (MMA), hydroxyropyl acrylate (HPA), sodium dodecyl sulfate (SDS), 2-ethylhexyl acrylate (2EHA), polyoxyethlene octyphenol ether (OP-10), $p$-toluenesulfonic acid ( $p$-TSA) and potassium persulfate $\left(\mathrm{K}_{2} \mathrm{~S}_{2} \mathrm{O}_{8}\right)$ were obtained from Aladdin (Southern California, L.A, USA). Sodium bicarbonate $\left(\mathrm{NaHCO}_{3}\right)$, ammonium acetate $\left(\mathrm{NH}_{4} \mathrm{Ac}\right)$, ammonia, glacial acetic acid (HAc), L(+)-ascorbic acid, and sodium acetate anhydrous were supplied by Guangzhou Chemical Reagent Factory (Guangzhou, China). Deionized water (DI water) was purified on a Milli-Q water-purification system (Milford, MA, USA). Tap water and river water were collected from our laboratory and the Pearl River (Guangzhou, China), respectively. The butterfish sample was purchased from Wal-Mart Stores (Guangzhou, China).

\section{Standard solutions}

Stock solutions (100 $\left.\mu \mathrm{g} \mathbf{~ m L}^{-1}\right) \cdot 10.0 \mathrm{mg}$ of MG, LMG, ThT and rosolic acid were weighed and put into a low-actinic $100 \mathrm{~mL}$ volumetric flask and diluted to a given volume with $\mathrm{MeOH}$. Each stock solution was stored at $-18{ }^{\circ} \mathrm{C}$ and freshly prepared every 6 months.

Intermediate solution I (1.0 $\mu \mathrm{g} \mathrm{mL}^{-1}$ and $\left.0.1 \mu \mathrm{g} \mathrm{mL} \mathrm{L}^{-1}\right)$. The intermediate solution was prepared by diluting the aboveprepared stock solution to a given volume with $\mathrm{MeOH}$. These solutions were freshly prepared monthly and stored at $4{ }^{\circ} \mathrm{C}$.

Working standard solutions I (DI water). A series of mixed standard solutions with MG and LMG, with concentrations of $0.1,0.5,1,5,10,20,50$ and $100 \mathrm{ng} \mathrm{mL}^{-1}$, were prepared by diluting MG and LMG intermediate solutions with DI water. Calibrants were used to prepare MG and LMG standard curves in water. Calibration standards were prepared every 1-2 days.

Working standard solutions II (fish matrix). Ammonium acetate $(0.1 \mathrm{M})$ buffer was prepared by dissolving $0.77 \mathrm{~g}$ of ammonium acetate in $100 \mathrm{~mL}$ of water and then adjusting the solution $\mathrm{pH}$ to 4.5 by adding $0.8 \mathrm{~mL}$ of acetic acid and $0.5 \mathrm{~mL}$ of $1 \mathrm{M} p$-TSA. A DDQ stock solution $(0.01 \mathrm{M})$ was prepared by adding $0.227 \mathrm{~g}$ of DDQ to a $100 \mathrm{~mL}$ volumetric flask and making it up to a given volume with acetonitrile. A DDQ working solution $(0.001 \mathrm{M})$ was prepared by addition of an aliquot $(10 \mathrm{~mL})$ of the DDQ stock solution into a $100 \mathrm{~mL}$ volumetric flask and diluting to the mark with acetonitrile. This solution was stored in a tightly capped bottle in a refrigerator with the temperature set to $4-8{ }^{\circ} \mathrm{C}$. A series of $\mathrm{MG}$ calibrants was prepared at concentrations of $0.1,0.5,1,5,10,20,50$ and $100 \mathrm{ng} \mathrm{mL}^{-1}$ using acidic acetonitrile. The acetonitrile was mixed with acetate buffer (0.05 $\mathrm{M}, \mathrm{pH} 4.5)$ and ascorbic acid (1 $\left.\mathrm{mg} \mathrm{mL}^{-1}\right)$ in a volume ratio of $47.5: 47.5: 5$. A DDQ solution $(0.001 \mathrm{M})$ was also adopted to assist in the mixing. Calibrants were used to generate a MG standard curve as for the fish sample. Calibration standards were prepared each time the experiment was carried out.

\section{Preparation of MIPCWT-SPME probes}

Preparation of probes. The wooden toothpicks were cut to $\sim 2 \mathrm{~cm}$ length, with the tip end further sharpened to have an external size in the range of $150-200 \mu \mathrm{m} .{ }^{34}$ Then, the sharpened wooden tips were immersed into anhydrous ethanol for $20 \mathrm{~min}$, followed by drying and then storing at room temperature for later use.

Preparation of emulsions. The aqueous silicone-modified acrylate molecularly imprinted emulsion (SMAMIE) was synthesized by seed emulsion polymerization. ${ }^{75}$ It is worth pointing out that the silicone composition was used to lock MIPs on the wooden tip. Firstly, acrylate functional monomer including $0.3 \mathrm{~g}$ of MMA, $0.15 \mathrm{~g}$ of AA, $0.6 \mathrm{~g}$ of St, $0.6 \mathrm{~g}$ of HPA, $4.5 \mathrm{~g}$ of 2-EHA and $4.5 \mathrm{~g}$ of BA were dissolved into $24 \mathrm{~mL}$ of DI water, followed by adding $0.15 \mathrm{~g}$ of OP-10 and SDS emulsifier under $20000 \mathrm{rpm}$ vigorous stirring for $15 \mathrm{~min}$ to form a preemulsion. In a four-necked round-bottom flask equipped with a mechanical stirrer, a reflux condenser, a temperature controller and an additional funnel, the $7.5 \mathrm{~g}$ of pre-emulsion, $13 \mathrm{~mL}$ of $1.2 \mathrm{mmol} \mathrm{L}^{-1} \mathrm{NaHCO}_{3}$ solution and $2.5 \mathrm{~mL}$ of $0.11 \mathrm{~mol} \mathrm{~L}^{-1} \mathrm{~K}_{2} \mathrm{~S}_{2} \mathrm{O}_{8}$ solution were added in the reactor and refluxed at $80{ }^{\circ} \mathrm{C}$ for $1 \mathrm{~h}$ to obtain a seed latex. Then, the remaining pre-emulsion and $2.5 \mathrm{~mL}$ of a $0.11 \mathrm{~mol} \mathrm{~L}^{-1} \mathrm{~K}_{2} \mathrm{~S}_{2} \mathrm{O}_{8}$ solution were fed through an addition funnel over the course of 3-4 h. Afterwards, A-172 was added dropwise to the mixture over $30 \mathrm{~min}$. After addition of all the monomers, the reaction mixture was maintained at $80^{\circ} \mathrm{C}$ for an additional $1 \mathrm{~h}$ to complete the polymerization. Then, a stoichiometric amount of MG was added to the resulting aqueous emulsion after the mixture was cooled to room temperature, finally producing SMAMIE.

Preparation of MIPCWT-SPME probes. The processed wooden toothpicks were dispersed in $100 \mathrm{~mL}$ of SMAMIE with $30 \mathrm{mg} \mathrm{L}{ }^{-1} \mathrm{MG}$ as the template for $15 \mathrm{~min}$. Moulding was carried out at $120{ }^{\circ} \mathrm{C}$ for thermochemical polymerization for $30 \mathrm{~min}$ to obtain the MIM. After the templates were removed, the MIPCWT-SPME probes were prepared by washing with a copious mixture of $\mathrm{MeOH}$ and $\mathrm{NH}_{4} \mathrm{Ac}$ (95:5, v/v), followed by $\mathrm{MeOH}$, and then drying.

\section{Characterization of the prepared MIPCWT-SPME probe}

Scanning electron microscope (SEM) and elemental mapping images analyses were performed on a S4800 field emission SEM instrument (Hitachi, Japan). Fourier transform-infrared spectroscopy (FTIR) analysis was conducted on a Cary 630 Fourier transform infrared spectrometer (Agilent Technologies, USA). 


\section{Extraction}

For the water sample. The MIPCWT-SPME probe was rinsed with $\mathrm{MeOH}$ for $30 \mathrm{~s}$, dried out, and then used for extraction of $100 \mathrm{~mL}$ of the untreated water sample under direct immersion for $40 \mathrm{~min}$ and then $400 \mathrm{rpm}$ stirring conditions. Upon extraction, the MIPCWT-SPME probe was rinsed quickly with DI water for $10 \mathrm{~s}$, and then dried out for analysis.

For the fish sample. The Ctenopharyngodon idellus tissue was first processed to remove scales and leave intact skin, and then cut into 3-5 $\mathrm{cm}$ sized cubes to be minced uniformly with a food blender. The homogenized fish samples of Ctenopharyngodon idellus were extracted according to the method of Fallah et al. ${ }^{76,77}$ using the DDQ solution to oxidize colorless LMG to its chromic analog, MG. A total amount of $5.0 \mathrm{~g}$ of the homogenized fish sample was accurately weighed and equably mixed with $16 \mathrm{~mL}$ of acidic acetonitrile in a $50 \mathrm{~mL}$ falcon tube. The homogenate was diluted to $25 \mathrm{~mL}$ with dichloromethane, ultrasonically extracted for $15 \mathrm{~min}$, and then centrifuged at $1500 \mathrm{rpm}$ for $10 \mathrm{~min}$. Subsequently, after $10 \mathrm{~mL}$ of the supernatant was transferred to another tube, $3 \mathrm{~mL}$ of the DDQ solution ( $0.001 \mathrm{M})$ was added. This oxidation reaction was allowed to proceed for $30 \mathrm{~min}$ with periodic agitation. The oxidized sample was evaporated to about $3 \mathrm{~mL}$ under a stream of nitrogen at room temperature, and then diluted with $20 \mathrm{~mL}$ of DI water. The MIPCWT-SPME probe was immersed in the oxidized sample for $40 \mathrm{~min}$ for extraction with $400 \mathrm{rpm}$ stirring. After extraction, the MIPCWT-SPME probe was rinsed quickly with DI water for $10 \mathrm{~s}$, and then dried out for further analysis.

\section{Detection}

The loaded MIPCWT-SPME probe was mounted onto a threedimensional moving stage, with the probe tip pointed to the MS inlet and adjusted to a position $10 \mathrm{~mm}$ away from the MS inlet. ${ }^{34}$ Afterwards, a high voltage of $4.5 \mathrm{kV}$ released from the MS was applied to the probe. Subsequently, as a spray solvent, $10 \mu \mathrm{L}$ of a mixture of $\mathrm{MeOH}$ and glacial acetic acid (99:1, v/v) was added onto the probe surface by a micropipette, for electrospray ionization mass spectrometric analysis.

\section{Mass spectrometry}

The mass spectrometric analysis was performed on a 6540 UHD Accurate-Mass Quadrupole Time-of-Flight mass spectrometer
(Agilent Technologies, Santa Clara, USA). The ionization source was set up using the corresponding ESI configuration. The quadrupole time-of-flight mass spectrometer was operated in total transmission ion mode, with the experimental conditions shown in Table 1. Experimental control and MS data acquisition were conducted via Qualitative Analysis B.06.00 software (Agilent Technologies, Santa Clara, USA).

\section{Quantitative calculation}

Quantitative analysis was performed using the internal standard (IS) calibration curve method. Blank DI water was spiked with a series of concentrations of MG and LMG standards in order to establish the calibration curves in aqueous solution. For establishing the calibration curves in the fish sample, the homogenized fish matrixes were added to the MG standards at a series of concentrations. $d_{5}$-MG was used as the IS for the analysis of MG, LMG, CV, LCV, ThT and rosolic acid. The IS compound was added into the spray solvent at a concentration of $50 \mathrm{ng} \mathrm{mL}^{-1}$. The peak area ratios of fragment ions $(A)$ generated from the target analyte to those from the corresponding IS compounds $\left(A_{\text {IS }}\right)$ were used for quantitative calculation.

\section{Results and discussion}

\section{Optimization of the preparation conditions of MIPCWT-SPME probes}

The preparation conditions of the MIPCWT-SPME probes include the eluent and elution time of the template (MG), and the dosage of the template. The eluent and elution time for processing the probe were first confirmed by immersing the probes with the template into $\mathrm{MeOH}, \mathrm{ACN}$, a mixture of $\mathrm{MeOH}$ and $\mathrm{NH}_{4} \mathrm{Ac}(95: 5, \mathrm{v} / \mathrm{v})$, and a mixture of $\mathrm{ACN}$ and $\mathrm{NH}_{4} \mathrm{Ac}$ (95:5, $\mathrm{v} / \mathrm{v})$ to wash the template for $12 \mathrm{~h}, 24 \mathrm{~h}, 36 \mathrm{~h}$ and $48 \mathrm{~h}$ at $100 \mathrm{rpm}$. The eluent was replaced every $12 \mathrm{~h}$. The eluent of each cycle was monitored by an ultraviolet spectrophotometer at $618 \mathrm{~nm}$ to investigate the elution of the template for the probes. These probes were washed for four cycles, and for each cycle, mass spectrometry was used for the measurement. As shown in Fig. 2b, the absorbance value of the mixture of $\mathrm{MeOH}$ and $\mathrm{NH}_{4} \mathrm{Ac}(95: 5, \mathrm{v} / \mathrm{v})$ decreased steeply with elution time. It can also be seen that the signal intensities increased with increasing sample volume, and equilibrium was reached at $100 \mathrm{~mL}$ for most of the MG and LMG. Note that the extraction time and

Table 1 Total transmission ion conditions for quantitative analysis of MG and its analogue using a quadrupole time-of-flight mass spectrometer

\begin{tabular}{|c|c|c|c|c|c|}
\hline MG & $\mathrm{C}_{23} \mathrm{H}_{25} \mathrm{ClN}_{2}$ & 364.1706 & 329.2012 & 180 & 4500 \\
\hline LMG & $\mathrm{C}_{23} \mathrm{H}_{26} \mathrm{~N}_{2}$ & 330.2096 & 331.2168 & 180 & 4500 \\
\hline Rosolic acid & $\mathrm{C}_{19} \mathrm{H}_{14} \mathrm{O}_{3}$ & 290.0942 & 291.1015 & 200 & 4500 \\
\hline$d_{6}-\mathrm{MG}^{a}$ & $\mathrm{C}_{29} \mathrm{H}_{22} \mathrm{D}_{5} \mathrm{~N}_{5} \mathrm{O}_{7}$ & 562.6012 & 334.2326 & 180 & 4500 \\
\hline
\end{tabular}

${ }^{a}$ Internal standard. 

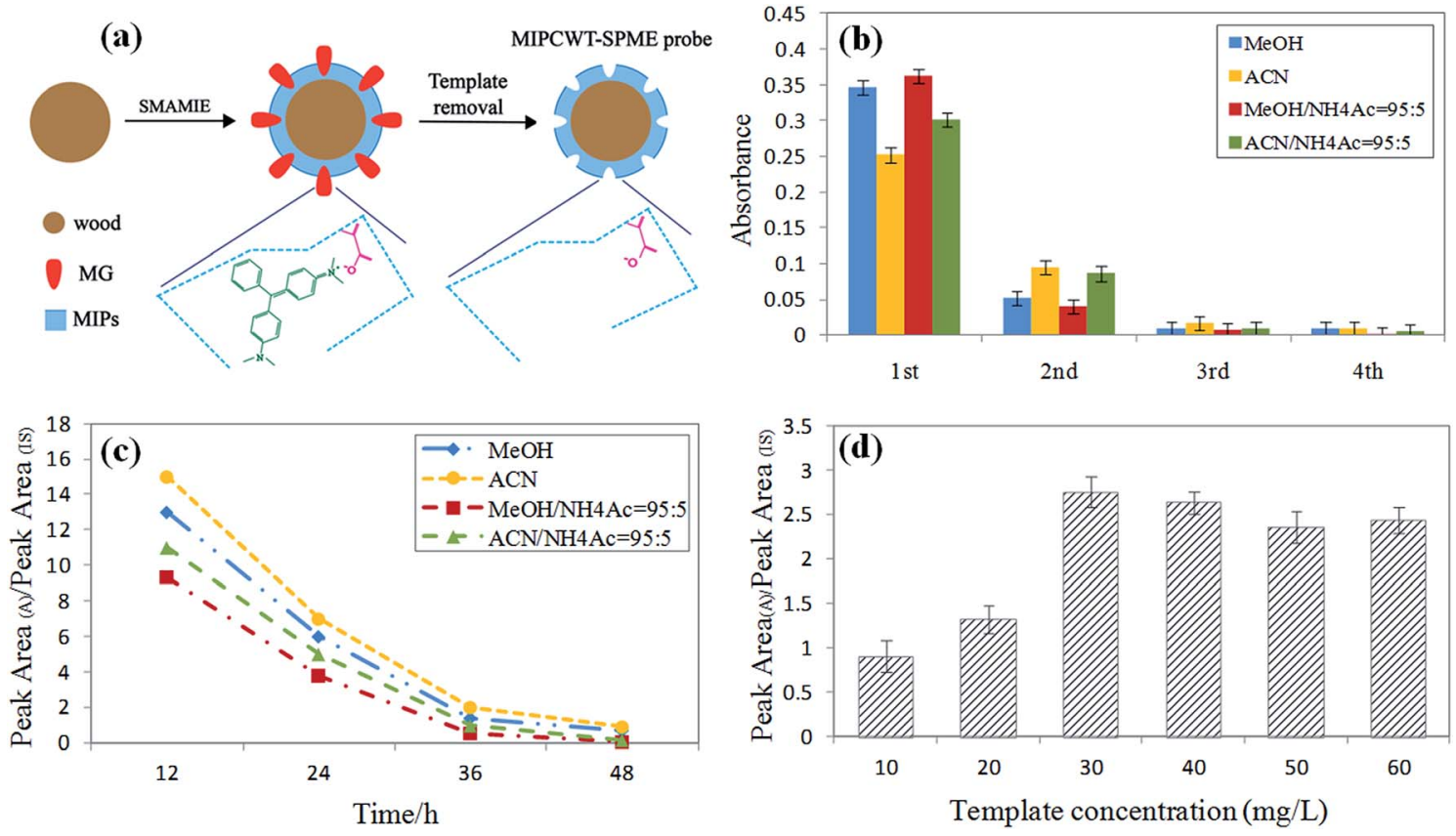

Fig. 2 Optimization of the preparation conditions of the MIPCWT-SPME probe. (a) A schematic diagram showing the preparation of the MIPCWT-SPME probe. (b) Histograms of the UV/Vis absorbance of eluents vs. elusion time for different elution systems with various elution solvents; each cycle has a $12 \mathrm{~h}$ interval. (c) Plots of the ratio of the characteristic MS peak area (A) to the peak area (IS) as a function of elution time using different elution solvents. (d) Study of the impact of the MIT template concentration on the ratio of the characteristic MS peak area (A) to the IS peak area.

sample dosage were optimized by means of analyzing water samples spiked with $50 \mathrm{ng} \mathrm{mL}^{-1}$ of MG and LMG. Different extraction times $(5,10,20,30,40,50$, and $60 \mathrm{~min})$ were also studied because the distribution of analytes between the sample solution and the MIPCWT-SPME probe is a dynamic equilibrium process. For MG and LMG, the results demonstrate that the signal intensities become steady after the highest peak emerged at $40 \mathrm{~min}$. Then, different sample volumes of 5, 10, 50, 100,150 , and $200 \mathrm{~mL}$ were investigated. It can be noted that the signal intensities increased with increasing sample volume, with an equilibrium reached at $100 \mathrm{~mL}$ for most of the MG and LMG.

\section{Characterization of the MIPCWT-SPME probe}

A layer of MIM can be observed on the MIPCWT-SPME probe surface by SEM (Fig. 3), which completely covers the porous structure of the wooden fiber. The selective extraction of MIM affords a high specific surface area for conjunction with MG analytes, as well as microchannels that facilitate transportation of the solvent to achieve ambient ionization for mass spectrometric analysis.

FTIR experiments were applied to confirm the success of the modification, as shown in Fig. 4. In contrast to the original wooden tip, the MIPCWT-SPME probe surface of our modified wooden tip can be evidenced through several relatively strong characteristic peaks indexed to the $\mathrm{C}=\mathrm{O}$ group at about $1730 \mathrm{~cm}^{-1}$, a C-O-C group at about 1160 and $1118 \mathrm{~cm}^{-1}$ (symmetric stretching vibration), and a $\mathrm{C}-\mathrm{O}-\mathrm{C}$ group at $1241 \mathrm{~cm}^{-1}$ (asymmetric stretching vibration). The characteristic peak at $1062 \mathrm{~cm}^{-1}$ can be ascribed to the stretching vibration of the Si-O bond. These FTIR absorptions are attributed to the existence of the SMAMIE, illuminating the successful synthesis of MIPs by the SMAMIE. All these results reveal the effective incorporation of adsorbents onto the MIPCWT-SPME probe surface.

To further analyze the chemical structure of our fabricated probe, the elemental distribution of MIM on the MIPCWTSPME probe surface was obtained by elemental mapping (Fig. 5). It can be seen that the MIPCWT-SPME probe surface is composed of a large amount of carbon (C), and a portion of oxygen (O) and silicon (Si) elements, of which $\mathrm{C}$ occupies the highest atomic percentage. It can also be seen that the MIM possesses $\mathrm{Si}$ element stemming from SMAMIE, and $\mathrm{C}$ and $\mathrm{O}$ elements from acrylics. Acrylics consist of short carbon chains, where $\mathrm{C}$ occupies the greatest atomic percentage.

\section{Optimization of extraction and desorption conditions}

The extraction conditions, including extraction time and sample volume, were optimized by analyzing DI water samples spiked with $50 \mathrm{ng} \mathrm{mL}^{-1}$ of MG and LMG. First, different extraction times $(5,10,20,30,40,50$, and $60 \mathrm{~min})$ were studied because the distribution of analytes between the sample solution and the MIPCWT-SPME probe is a dynamic equilibrium process. As shown in Fig. 6a, the results demonstrate that the signal intensities, for MG and LMG, become steady after the highest peak appeared at $40 \mathrm{~min}$. Then, different sample volumes of $5,10,50,100,150$, and $200 \mathrm{~mL}$ were investigated. It was found that the signal intensities increased with increasing 

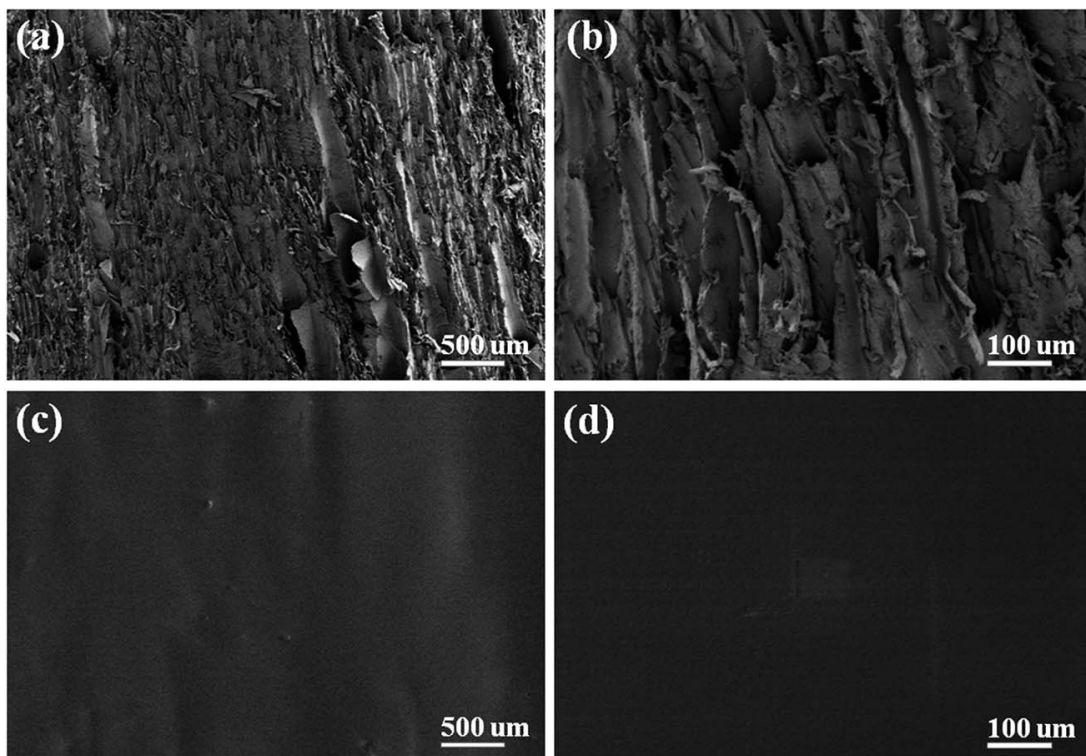

Fig. 3 SEM images at different magnifications of $100 \times$ (a) and $500 \times$ (b) of the pristine wooden tip, and of $100 \times(c), 500 \times(d)$ of the MIPCWTSPME probe.

sample volume, and equilibrium was reached at $100 \mathrm{~mL}$ for most of the MG and LMG (Fig. 6b).

The desorption conditions are vital to the direct analysis of MG and LMG for ambient ionization for mass spectrometric analysis. The signals of the spray solvent can be observed, including $\mathrm{MeOH}, \mathrm{ACN}$, a mixture of $\mathrm{MeOH}$ and $\mathrm{HAc}(9: 1, \mathrm{v} / \mathrm{v})$, a mixture of ACN and HAc $(9: 1, \mathrm{v} / \mathrm{v})$, a mixture of $\mathrm{MeOH}$ and $\operatorname{HAc}(99: 1, v / v)$, and a mixture of ACN and HAc $(99: 1, v / v)$. The obtained results show that the signal intensities increased with decreasing solution $\mathrm{pH}$ values. Because MG and LMG are polar compounds, the solution $\mathrm{pH}$ value can be lowered to some extent, causing the MG and LMG to ionize easily. Furthermore, $\mathrm{MeOH}$ with acid can shift the equilibrium towards the molecular form, thereby increasing their affinity for the sorbent.

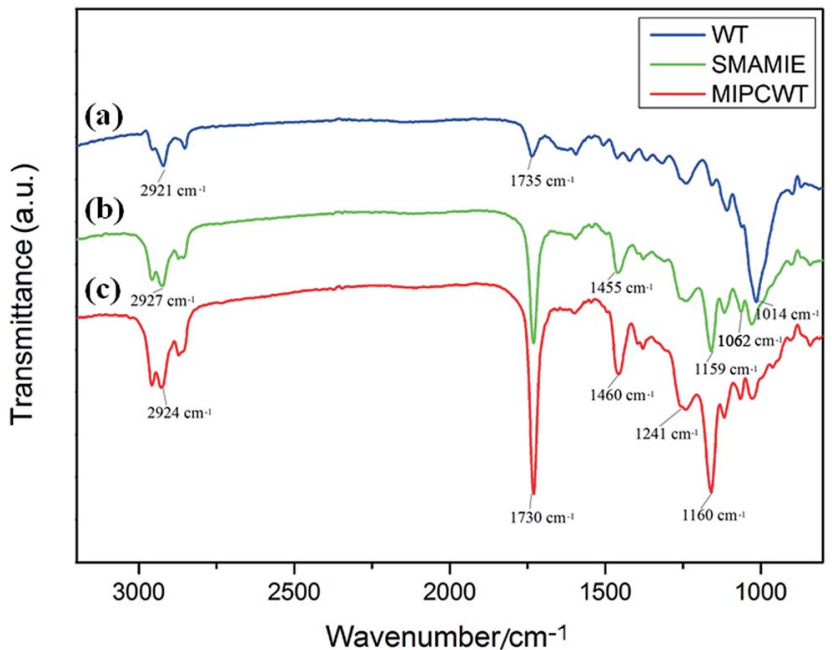

Fig. 4 FTIR spectra of the pristine wooden-tip surface (a), and SMAMIE (b) and MIPCWT-SPME (c) probe surfaces.
Compared to ACN, $\mathrm{MeOH}$ can be ionized with a lower ionization energy, which endows the spray solvent, namely the mixture of $\mathrm{MeOH}$ and HAc $(99: 1, \mathrm{v} / \mathrm{v})$, with a remarkable extraction and ionization efficiency (Fig. 6c).

\section{Selective extraction properties}

Considering that malachite green and its metabolite are triphenylmethane compounds containing triphenylmethane and amidogen structures, the selective extraction of MIPs on the surface of wooden tips is based on the specific recognition sites matching either triphenylmethane or amidogen groups. The structural formulae of verified compounds are shown in Fig. 7a. The selective extraction properties of MIPCWT-SPME probes
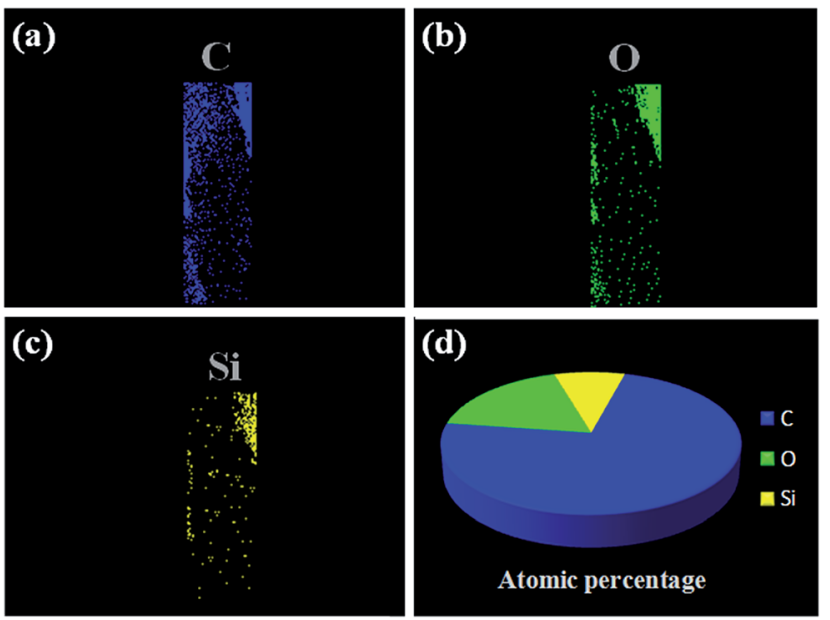

Fig. 5 Elemental mapping images of the MIPCWT-SPME probe. Elemental distribution of $\mathrm{C}(\mathrm{a}), \mathrm{O}$ (b), and $\mathrm{Si}$ (c). (d) The atomic percentages of $\mathrm{C}, \mathrm{O}$, and $\mathrm{Si}$. 

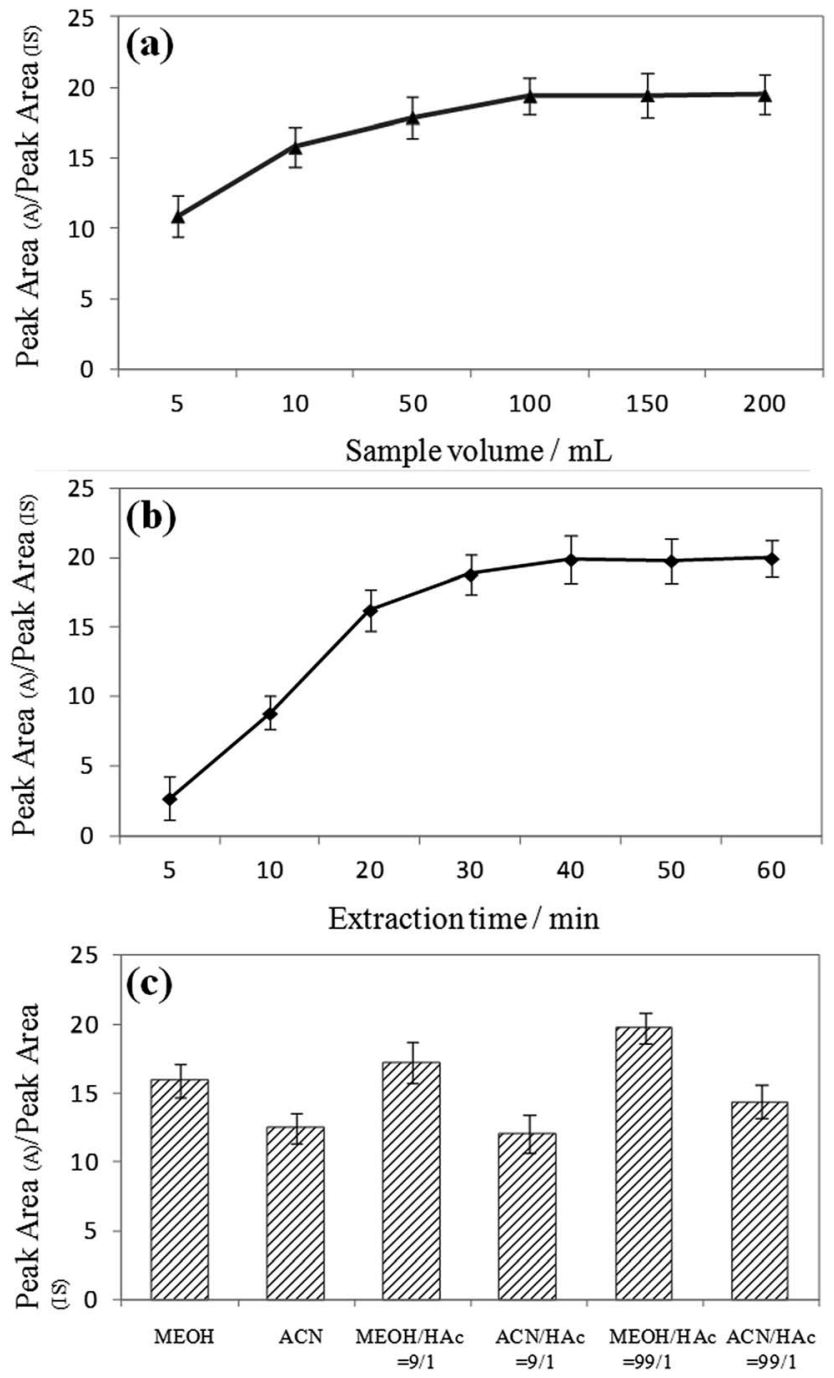

Fig. 6 Optimization of the extraction and desorption conditions under which the MIPCWT-SPME probe was prepared. (a) Plots of the ratio of the characteristic MS peak area $(A)$ to the IS peak area as a function of sample extraction volume. (b) Plots of the ratio of the characteristic MS peak area $(A)$ to the IS peak area as a function of extraction time. (c) The impact of the different spray solvents on the ratio of the characteristic MS peak area $(A)$ to the IS peak area.

were investigated by extracting $50 \mathrm{ng} \mathrm{mL}^{-1}$ of hybrid intermediate solutions including MG, LMG, CV, LCV, ThT and rosolic acid for $40 \mathrm{~min}$. The extracted MIPCWT-SPME probe tip was placed pointing to the MS inlet, with $4.5 \mathrm{kV}$ applied to the probe. An aliquot of $10 \mu \mathrm{L}$ of the mixture of $\mathrm{MeOH}$ and $\mathrm{HAc}$ ( $99: 1, \mathrm{v} / \mathrm{v})$, together with $50 \mathrm{ng} \mathrm{mL}^{-1}$ IS compound $\left(d_{5}-\mathrm{MG}\right)$, was added onto the probe surface for mass spectrometric analysis. The experimental results demonstrate that the adsorption of the amidogen groups (CV, LCV and ThT) is much higher as compared to those with only triphenylmethane groups (rosolic acid), as shown in Fig. 7b. The data thus indicate that the MIPs of the MIPCWT-SPME probe are primarily extracted by the compounds containing amidogen groups, leading us to improve the selective and specific extraction of trace level compounds.
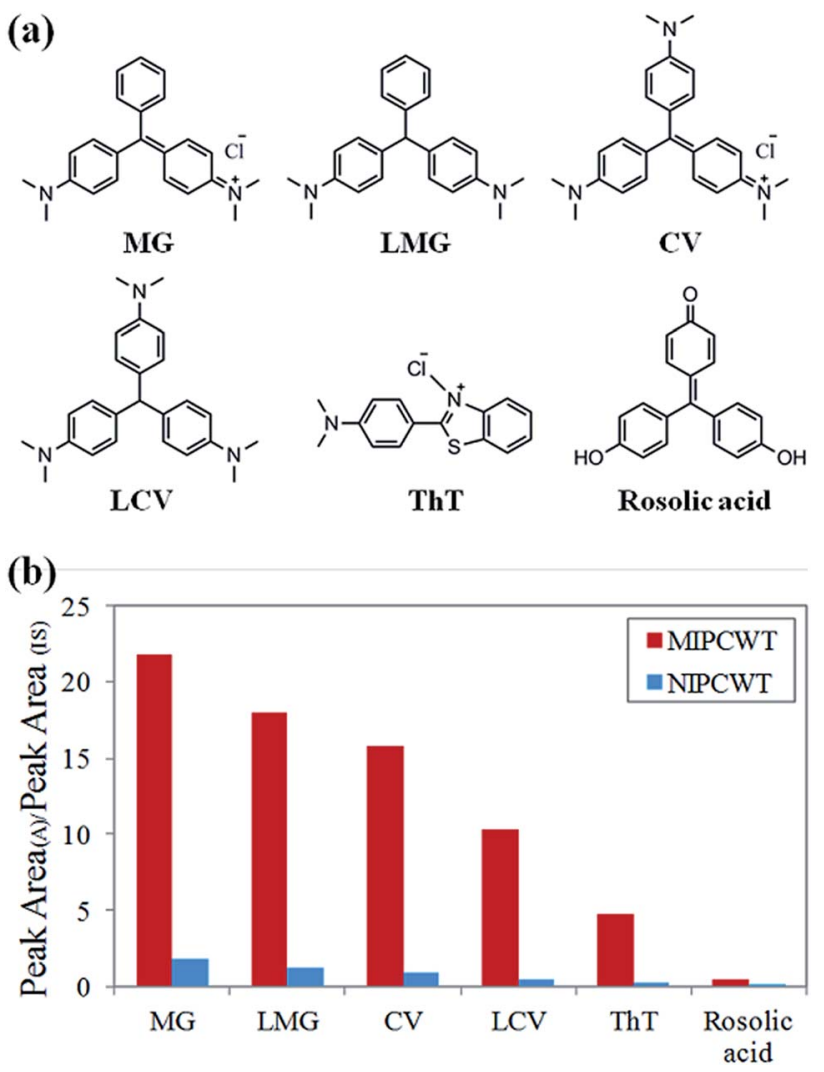

Fig. 7 Study of the selective extraction conditions of the MIPCWTSPME probe and the NIPCWT-SPME probe. (a) Chemical structures of the selectively extracted compounds. (b) Plots of the ratio of the characteristic MS peak area $(A)$ to the IS peak area as a function of selective extraction between the MIPCWT-SPME probe and the NIPCWT-SPME probe.

\section{Extraction properties}

The extraction properties were investigated by determining the enrichment factor (EF, defined as the ratio of the $A / A_{\mathrm{IS}}$ obtained by MIPCWT-SPME probe to that of the original wooden tip) of each analyte in DI water. A $100 \mathrm{~mL}$ aliquot of $50 \mathrm{ng} \mathrm{mL}^{-1}$ spiked DI water sample was used for the study. The results show that the developed SPME probe possessed excellent extraction capacity for analysis of aqueous samples, with EF values of 1877 \pm 241 and $1502 \pm 232$ for MG and LMG, respectively. All these results demonstrate that the proposed MIPCWT-ESI-MS method is suitable for direct quantitative determination of trace levels of malachite green and its metabolite.

\section{Quantitative analysis}

The quantitative analysis is based on the quantitative calculation of the DI water sample and fish sample through optimization via analyzing the DI water sample spiked with MG and LMG at a series of concentrations, as well as the fish sample with MG at a series of concentrations. Quantitative calculation was performed using the IS calibration curve method. Into the spray solvent, $d_{5}$-MG was added at a concentration of $50 \mathrm{ng} \mathrm{mL}^{-1}$ and used as the isotope IS 
Table 2 The linearity, LOD and repeatability of the MIPs-coated wooden-tip ESI-MS method

\begin{tabular}{|c|c|c|c|c|c|c|}
\hline Matrix & Analyte & $\begin{array}{l}\text { Linear range } \\
\left(\mathrm{ng} \mathrm{mL} \mathrm{mL}^{-1}\right)\end{array}$ & Regression equation & $R^{2}$ & $\mathrm{LOD}^{a}\left(\mathrm{ng} \mathrm{mL}^{-1}\right)$ & $\begin{array}{l}\text { Repeatability }^{b} \\
(\mathrm{RSD}, \%, n=6)\end{array}$ \\
\hline DI water & MG & $0.1-100$ & $y=0.0608 x+0.1128$ & 0.9990 & 0.01 & 4.6 \\
\hline Fish & MG & $0.1-100$ & $y=0.4991 x+1.0385$ & 0.9989 & 0.05 & 10.6 \\
\hline
\end{tabular}

${ }^{a}$ LOD was determined as the concentration producing a signal-to-noise ratio of $3 .{ }^{b}$ Analysis of DI water and fish samples spiked with $50 \mathrm{ng} \mathrm{mL}^{-1}$ analytes.

Table 3 Comparison of our method with a number of state-of-the-art methods reported for the detection of MG in aquatic products

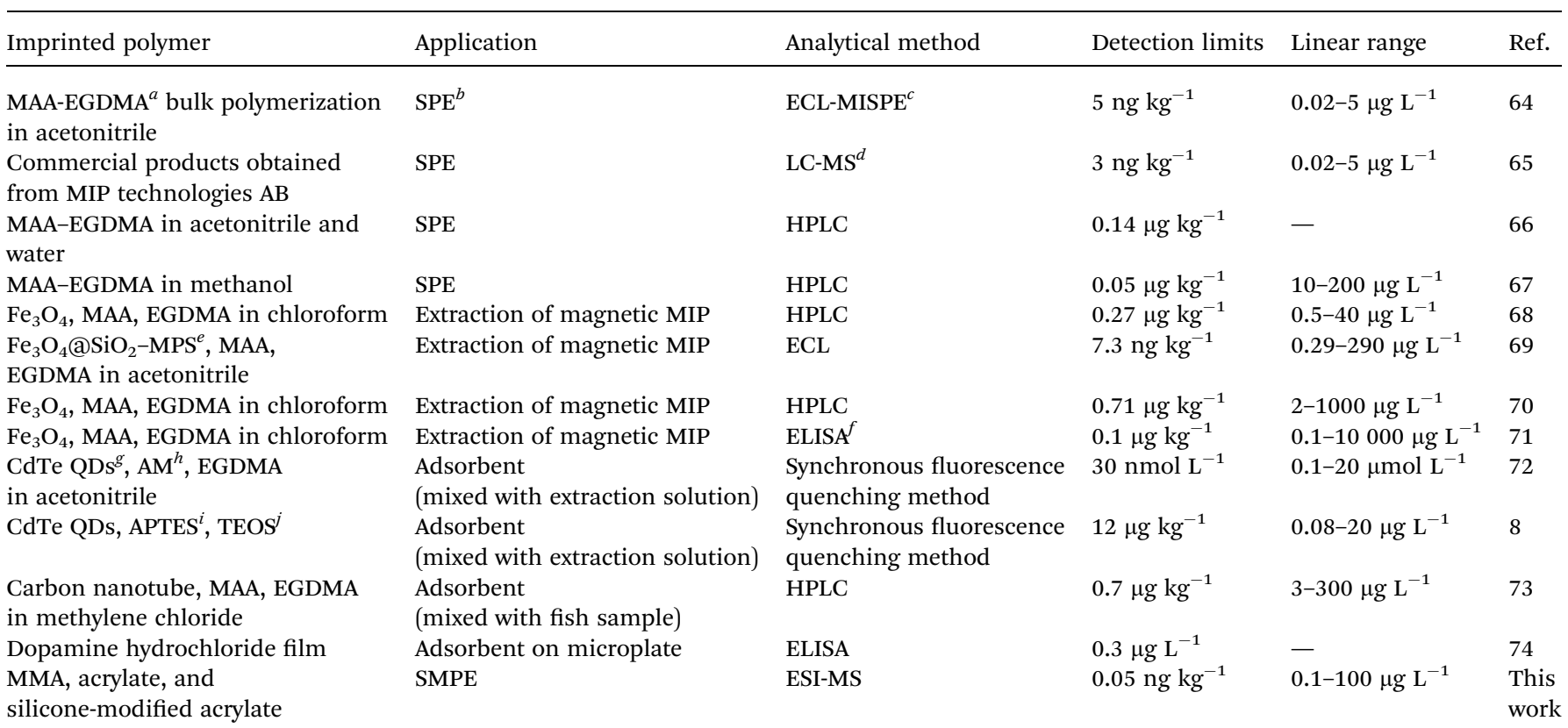

${ }^{a}$ Methacrylic acid-ethylene glycol dimethacrylate. ${ }^{b}$ Solid-phase extraction. ${ }^{c}$ Electrochemiluminescence-molecularly imprinted solid phase extraction. ${ }^{d}$ Liquid chromatography mass spectrometry. ${ }^{e} 3$-Methacryloxypropyltrimethoxy-silane. ${ }^{f}$ Enzyme-linked immunosorbent assay. ${ }^{g}$ Quantum dots. ${ }^{h}$ Acrylamide. ${ }^{i}$ (3-Aminopropyl)triethoxysilane. ${ }^{j}$ Tetraethyl orthosilicate.

compound. After MIPCWT-ESI-MS analysis, satisfactory linearity was obtained with impressive correlation coefficient values $\left(R^{2}\right)$ of no less than 0.9988 for MG and LMG in the concentration range of $0.1-100 \mathrm{ng} \mathrm{mL}^{-1}$ (Table 2). Under the optimal conditions, the latter protocol gives limits of detection (LOD) of $0.01 \mathrm{ng} \mathrm{L}^{-1}$ for MG and LMG in the DI water sample, and $0.05 \mathrm{ng} \mathrm{L}^{-1}$ for MG in the fish sample. Notably, the performance of our method in the detection of MG is superior to most of the state-of-the-art approaches recently reported, as displayed in Table 3.

To examine the repeatability, one SPME probe was used for six repeated extractions of the DI water samples spiked with 50 ng $\mathrm{mL}^{-1}$ of MG and LMG under the same conditions. Before reuse, the samples were washed with $10 \mathrm{~mL}$ of a mixture of $\mathrm{MeOH}$ and HAc $(99: 1, \mathrm{v} / \mathrm{v})$ for $5 \mathrm{~min}$. It should be noted that the relative standard deviations (RSD) of the repeated test results are less than 4.5 and 5.1\% regarding MG and LMG, respectively. It is worth pointing out that, although the wooden tip-based probes are disposable after use, they can be reused without significant loss of the excellent initial detection properties.

\section{Analysis of real-life samples}

The optimized surface-coated wooden-tip ESI-MS method was applied for analysis of real-life tap water, river water and fish samples, with the results shown in Table 4. No MG and LMG could be detected in tap water, but it is well demonstrated that the recoveries ranged from 93.7 to $102.8 \%$ in tap water. In one river water sample, MG and LMG were determined to be 0.8 and $0.3 \mathrm{ng} \mathrm{L}^{-1}$, respectively, with the recoveries ranging from 95.2 to $108.3 \%$. Considering that LMG could be oxidized to MG by DDQ in the fish sample, a large concentration of $3.4 \mathrm{ng} \mathrm{mL}^{-1}$ could be detected for MG, with the recoveries obtained in the range of 106.7 to $113.6 \%$. The satisfactory results of the recovery measurements confirm that the aqueous matrices do not affect the sorbent materials, which is of technological importance for trace analysis. 
Table 4 Original amounts and recoveries of MG and its metabolite in tap water, river water and fish samples

\begin{tabular}{|c|c|c|c|c|c|}
\hline \multirow[b]{2}{*}{ Matrix } & \multirow[b]{2}{*}{$\begin{array}{l}\text { Spiked } \\
\left(\text { ng mL }^{-1}\right)\end{array}$} & \multicolumn{2}{|l|}{ MG } & \multicolumn{2}{|l|}{ LMG } \\
\hline & & $\begin{array}{l}\text { Measured } \\
\left(\mathrm{ng} \mathrm{mL}^{-1}\right)\end{array}$ & $\begin{array}{l}\text { Recovery } \\
(\%)\end{array}$ & $\begin{array}{l}\text { Measured } \\
\left(\mathrm{ng} \mathrm{mL}^{-1}\right)\end{array}$ & $\begin{array}{l}\text { Recovery } \\
(\%)\end{array}$ \\
\hline Тар & 0 & N.D. ${ }^{a}$ & - & N.D. ${ }^{a}$ & - \\
\hline \multirow[t]{2}{*}{ water } & 10 & 10.3 & 103 & 43.4 & 97 \\
\hline & 50 & 48 & 96 & 424.5 & 93 \\
\hline \multirow[t]{3}{*}{ River water } & 0 & N.D. ${ }^{a}$ & - & N.D. ${ }^{a}$ & - \\
\hline & 10 & 10.8 & 108 & 43.3 & 98 \\
\hline & 50 & 47.5 & 95 & 438.0 & 92 \\
\hline \multirow[t]{3}{*}{ Fish } & 0 & N.D. ${ }^{a}$ & - & - & - \\
\hline & 10 & 11.3 & 113 & - & - \\
\hline & 50 & 55.1 & 106 & - & - \\
\hline
\end{tabular}

\section{Conclusions}

A molecularly imprinted polymer-coated wooden-tip solidphase micro-extraction (MIPCWT-SPME) probe has been fabricated by applying a silicone-modified acrylate molecularly imprinted emulsion (SMAMIE) onto the surface of wooden tips. Such a novel probe can be used for efficient extraction of malachite green, realizing sensitive detection and analysis. Using the cost-effective and portable MIPCWT-SPME probe as the key component, the MIPCWT-ESI-MS method has been developed for rapid and sensitive analysis of trace malachite green and its metabolite in real-life water and fish samples. The method proposed here possesses the advantages of simplicity, quantitativeness, reproducibility, and high throughput, showing promising prospects for rapid and sensitive detection of trace malachite green and its metabolite in aquatic products.

\section{Conflicts of interest}

There are no conflicts to declare.

\section{Acknowledgements}

The financial support from the Science and Technology Project of Guangdong Province, China (2015A030401106, 2017A070702017, 2016A040403057, 2016A040403061, 2015A020218001 and 2013B031500003), the Innovation Project of Department of Education of Guangdong Province (2015KTSCX150), the Science and Technology Project of Foshan City (2015AG10011 and 2016GA10162), GDAS' Special Project of Science and Technology Development (No. 2017GDASCX-0104 and 2016GDASPT-0203), and Natural Science Foundation of Guangdong Province, China (No. 2017A030310233) are greatly acknowledged. We also thank Dr Jiewei Deng at Sun Yat-sen University for guidance of the paper.

\section{Notes and references}

1 L. Zhang, H. Zhang, W. Guo and Y. Tian, Appl. Clay Sci., 2014, 93, 85-93.
2 E. A. Dil, M. Ghaedi, A. Asfaram, S. Hajati, F. Mehrabi and A. Goudarzi, Ultrason. Sonochem., 2017, 34, 677-691.

3 S. Srivastava, R. Sinha and D. Roy, Aquat. Toxicol., 2004, 66, 319-329.

4 A. Stolker, T. Zuidema and M. Nielen, TrAC, Trends Anal. Chem., 2007, 26, 967-979.

5 F. Jia, X. Yang and Z. Li, RSC Adv., 2016, 6, 92723-92728.

6 Y. N. Rao, D. Banerjee, A. Datta, S. K. Das and A. Saha, RSC Adv., 2016, 6, 49083-49090.

7 X. Jiang, S. Wang, L. Ge, F. Lin, Q. Lu, T. Wang, B. Huang and B. Lu, RSC Adv., 2017, 7, 38965-38972.

8 L. Wu, Z.-z. Lin, H.-p. Zhong, A.-h. Peng, X.-m. Chen and Z.-y. Huang, Food Chem., 2017, 229, 847-853.

9 H. Zhang, F. Zhang and Q. Huang, RSC Adv., 2017, 7, 57905799.

10 F. Jing, R. Liang, J. Xiong, R. Chen, S. Zhang, Y. Li and L. Wu, Appl. Catal., B, 2017, 206, 9-15.

11 Z. Shi, L. Li, Y. Xiao, Y. Wang, K. Sun, H. Wang and L. Liu, RSC Adv., 2017, 7, 30904-30910.

12 R. G. Hemalatha, H. R. Naik, V. Mariappa and T. Pradeep, RSC Adv., 2015, 5, 50512-50522.

13 H. Zhang, H. Lu, H. Huang, J. Liu, X. Fang, B.-F. Yuan, Y.-Q. Feng and H. Chen, Anal. Chim. Acta, 2016, 926, 7278.

14 L. Song, J. Xu, K. Chingin, T. Zhu, Y. Zhang, Y. Tian, H. Chen and X. Chen, J. Agric. Food Chem., 2017, 65, 7006-7011.

15 L. A. Doezema, T. Longin, W. Cody, V. Perraud, M. L. Dawson, M. J. Ezell, J. Greaves, K. R. Johnson and B. J. Finlayson-Pitts, RSC Adv., 2012, 2, 2930-2938.

16 F. Zhou, S. Liu, J. Xing, F. Song, Z. Liu and S. Liu, RSC Adv., 2016, 6, 98927-98934.

17 X. Fan, C.-F. Wang, C.-Y. You, X.-Y. Wei, L. Chen, J.-P. Cao, Y.-P. Zhao, W. Zhao, Y.-G. Wang and J.-L. Lu, RSC Adv., 2016, 6, 105780-105785.

18 H.-Y. Hsieh, L.-H. Li, R.-Y. Hsu, W.-F. Kao, Y.-C. Huang and C.-C. Hsu, Anal. Chem., 2017, 89, 6147-6153.

19 K. Hiraoka, K. Nishidate, K. Mori, D. Asakawa and S. Suzuki, Rapid Commun. Mass Spectrom., 2007, 21, 3139-3144.

20 L. C. Chen, K. Nishidate, Y. Saito, K. Mori, D. Asakawa, S. Takeda, T. Kubota, H. Hori and K. Hiraoka, J. Phys. Chem. B, 2008, 112, 11164-11170.

21 B. B. Wang, D. Gao, I. Levchenko, K. Ostrikov, M. Keidar, M. K. Zhu, K. Zheng and B. Gao, RSC Adv., 2016, 6, 8760787615.

22 H. Puliyalil, G. Filipic, J. Kovac, M. Mozetic, S. Thomas and U. Cvelbar, RSC Adv., 2016, 6, 95120-95128.

23 D. Chen, Y.-Q. Huang, X.-M. He, Z.-G. Shi and Y.-Q. Feng, Analyst, 2015, 140, 1731-1738.

24 D. Chen, H.-B. Zheng, Y.-Q. Huang, Y.-N. Hu, Q.-W. Yu, B.-F. Yuan and Y.-Q. Feng, Analyst, 2015, 140, 5662-5670.

25 J. A. Fincher, A. R. Korte, B. Reschke, N. J. Morris, M. J. Powell and A. Vertes, Analyst, 2017, 142, 3157-3164.

$26 \mathrm{H}$. Li and A. Vertes, Analyst, 2017, 142, 2921-2927.

27 F. A. M. G. van Geenen, M. C. R. Franssen, A. H. M. Schotman, H. Zuilhof and M. W. F. Nielen, Anal. Chem., 2017, 89, 4031-4037. 
28 S. F. Resende, J. A. R. Teodoro, I. Binatti, R. L. Gouveia, B. S. Oliveira and R. Augusti, Int. J. Mass Spectrom., 2016, 418, 107-111.

29 X. Wang, Y. Chen, Y. Zheng and Z. Zhang, Materials, 2017, 10, 769.

30 T. Wang, Y. Zheng, X. Wang, D. E. Austin and Z. Zhang, Anal. Chem., 2017, 89, 7988-7995.

31 L. Di Donna, D. Taverna, S. Indelicato, A. Napoli, G. Sindona and F. Mazzotti, Food Chem., 2017, 229, 354-357.

32 A. K. Meher and Y.-C. Chen, RSC Adv., 2015, 5, 94315-94320.

33 B. Hu, Y. Huang, G. Yin, G. Zhang, L. Zhang, T. Wang and Z.-P. Yao, Anal. Methods, 2016, 8, 6840-6846.

34 Y. Yang, J. Deng and Z.-P. Yao, Anal. Chim. Acta, 2015, 887, 127-137.

35 B.-c. Yang, F. Wang, W. Deng, Y. Zou, F.-y. Liu, X.-d. Wan, X. Yang, H. Liu and O.-p. Huang, Anal. Methods, 2015, 7, 5886-5890.

36 B.-c. Yang, F.-y. Liu, L.-q. Wang, Y. Zou, F. Wang, W. Deng, X.-d. Wan, X. Yang, M. He and O.-p. Huang, Anal. Methods, 2015, 7, 6125-6132.

37 B.-c. Yang, F.-y. Liu, J.-b. Guo, L. Wan, J. Wu, F. Wang, H. Liu and O.-p. Huang, Anal. Methods, 2015, 7, 2913-2916.

38 Q. Du, J. Deng, Y. Liu, X. Zhang, Y. Yang and J. Chen, Anal. Methods, 2015, 7, 4803-4810.

39 Y. Yang and J. Deng, Anal. Chim. Acta, 2014, 837, 83-92.

40 G.-Z. Xin, B. Hu, Z.-Q. Shi, Y. C. Lam, T. T.-X. Dong, P. Li, Z.-P. Yao and K. W. K. Tsim, Anal. Chim. Acta, 2014, 820, 84-91.

41 R. Parchami, M. Kamalabadi and N. Alizadeh, J. Chromatogr. A, 2017, 1481, 37-43.

42 G. A. Gomez-Rios, C. Liu, M. Tascon, N. Reyes-Garces, D. W. Arnold, T. R. Covey and J. Pawliszyn, Anal. Chem., 2017, 89, 3805-3809.

43 M. F. Mirabelli, J.-C. Wolf and R. Zenobi, Anal. Chem., 2016, 88, 7252-7258.

44 N. R. Choi, Y. P. Kim, W. H. Ji, G.-S. Hwang and Y. G. Ahn, Talanta, 2016, 148, 69-74.

45 F. D. S. Araujo, R. L. Vieira, E. P. L. Molano, H. J. Maximo, R. J. D. Dalio, P. H. Vendramini, W. L. Araujo and M. N. Eberlin, RSC Adv., 2017, 7, 29953-29958.

46 J. E. Giffen, J. Y. Rosati, C. M. Longo and R. A. Musah, Anal. Chem., 2017, 89, 7719-7726.

47 G. A. Gomez-Rios, E. Gionfriddo, J. Poole and J. Pawliszyn, Anal. Chem., 2017, 89, 7240-7248.

48 G. A. Gomez-Rios, T. Vasiljevic, E. Gionfriddo, M. Yu and J. Pawliszyn, Analyst, 2017, 142, 2928-2935.

49 A. Nicolas Filippin, J. Ramon Sanchez-Valencia, J. Idigoras, M. Macias-Montero, M. Alcaire, F. Javier Aparicio, J. Pedro Espinos, C. Lopez-Santos, F. Frutos, A. Barranco, J. Antonio Anta and A. Borras, Adv. Mater. Interfaces, 2017, 4, 1601233.

50 J. Chauvin, F. Judee, M. Yousfi, P. Vicendo and N. Merbahi, Sci. Rep., 2017, 7, 4562.

51 S. Ahmad, M. Tucker, N. Spooner, D. Murnane and U. Gerhard, Anal. Chem., 2015, 87, 754-759.
52 B.-C. Yang, S.-F. Fang, X.-J. Wan, Y. Luo, J.-Y. Zhou, Y. Li, Y.-J. Li, F. Wang and O.-P. Huang, Anal. Chim. Acta, 2017, 973, 68-74.

53 G. A. Gomez-Rios, N. Reyes-Garces, B. Bojko and J. Pawliszyn, Anal. Chem., 2016, 88, 1259-1265.

$54 \mathrm{H}$. Amanzadeh, Y. Yamini, M. Moradi and Y. A. Asl, J. Chromatogr. A, 2016, 1465, 38-46.

55 M. Tascon, G. A. Gomez-Rios, N. Reyes-Garces, J. Poole, E. Boyaci and J. Pawliszyn, Anal. Chem., 2017, 89, 8421-8428.

56 M. Tascon, G. A. Gomez-Rios, N. Reyes-Garces, J. Poole, E. Boyaci and J. Pawliszyn, Sci. Rep., 2017, 144, 106-111.

57 G. A. Gomez-Rios and J. Pawliszyn, Angew. Chem., Int. Ed., 2014, 53, 14503-14507.

58 J. Deng, T. Yu, Y. Yao, Q. Peng, L. Luo, B. Chen, X. Wang, Y. Yang and T. Luan, Anal. Chim. Acta, 2017, 954, 52-59.

59 J. Deng, Y. Yang, L. Fang, L. Lin, H. Zhou and T. Luan, Anal. Chem., 2014, 86, 11159-11166.

60 P. Regal, M. Díaz-Bao, R. Barreiro, A. Cepeda and C. Fente, Cent. Eur. J. Chem., 2012, 10, 766-784.

61 A. Speltini, A. Scalabrini, F. Maraschi, M. Sturini and A. Profumo, Anal. Chim. Acta, 2017, 974, 1-26.

62 R. Mirzajani and M. Bagheban, Int. J. Environ. Anal. Chem., 2016, 96, 576-594.

63 S. Ansari, TrAC, Trends Anal. Chem., 2017, 90, 89-106.

64 Z. Guo, P. Gai, T. Hao, J. Duan and S. Wang, J. Agric. Food Chem., 2011, 59, 5257-5262.

65 M. J. Martinez Bueno, S. Herrera, A. Ucles, A. Aguera, M. D. Hernando, O. Shimelis, M. Rudolfsson and A. R. Fernandez-Alba, Anal. Chim. Acta, 2010, 665, 47-54.

66 C. Long, Z. Mai, Y. Yang, B. Zhu, X. Xu, L. Lu and X. Zou, J. Chromatogr. A, 2009, 1216, 2275-2281.

67 Z. Lian and J. Wang, Mar. Pollut. Bull., 2012, 64, 2656-2662.

68 Z.-z. Lin, H.-y. Zhang, A.-h. Peng, Y.-d. Lin, L. Li and Z.-y. Huang, Food Chem., 2016, 200, 32-37.

69 B. Huang, X. Zhou, J. Chen, G. Wu and X. Lu, Talanta, 2015, 142, 228-234.

70 Z.-z. Lin, H.-y. Zhang, L. Li and Z.-y. Huang, React. Funct. Polym., 2016, 98, 24-30.

71 L. Li, Z. Z. Lin, A. H. Peng, H. P. Zhong, X. M. Chen and Z. Y. Huang, J. Chromatogr. B: Anal. Technol. Biomed. Life Sci., 2016, 1035, 25-30.

72 J. Yang, Z.-Z. Lin, H.-P. Zhong, X.-M. Chen and Z.-Y. Huang, Sens. Actuators, B, 2017, 252, 561-567.

73 Y. Wang and L. Chen, J. Chromatogr. B: Anal. Technol. Biomed. Life Sci., 2015, 1002, 98-106.

74 L. Li, A.-h. Peng, Z.-z. Lin, H.-p. Zhong, X.-m. Chen and Z.-y. Huang, Food Chem., 2017, 229, 403-408.

75 J. Ou, Y. Yang, J. Gan, C. Ha and M. Zhang, J. Appl. Polym. Sci., 2014, 131, 2540.

76 W. C. Andersen, S. B. Turnipseed and J. E. Roybal, J. Agric. Food Chem., 2006, 54, 4517-4523.

77 A. A. Fallah and A. Barani, Food Control, 2014, 40, 100105. 